\title{
Risk and medical ethics
}

\section{Author's abstract}

Quantitative estimates of risk, and their comparison with quantitative estimates of benefit, contribute usefully to decision-making in many fields. In medicine, our assessments of the probability of harm, and of the likelihood of benefit, resulting from many procedures are at present very limited. Moreover, the comparison of risk and of benefit is difficult to make in any quantitative way, whether for a procedure in general or, even more so, for its application in any particular patient. Yet it must be ethically insecure to propose or to use a procedure without some assessment, however approximate, of the hazards involved, and without some indication of whether those hazards will be clearly offset by the likelihood of benefit that should result from use of the procedure.

In medicine, as in many other fields, the long familiar problems of balancing risk and benefit are being looked at in an increasingly quantitative way.

There are many reasons for this. Bolder surgical and pharmacological methods have become possible in the treatment of severe or life threatening disease. Are the greater hazards of the treatment clearly outweighed by the better cures or palliations that they achieve? Healthy people are being screened in various ways for the early detection of malignant disease. Could any of these mass screening procedures, and particularly those involving some radiation exposure to large numbers of people, be liable to cause more disease than they detect or prevent? Or, to press this question more sharply, above what age do you gain, on balance, by such radiological screening, and below what age do you lose? Similar problems occur with vaccinations. What is the break-even point for mass immunisation against diseases which, with the widespread use of immunisation, have become less frequent? Such questions ask for quantitative answers, and it is ethically insecure to have to proceed without such answers, or without trying to obtain them. And many people must surely have the responsible attitude of wishing to possess solid

\section{Key words}

Risk; risk-benefit analysis; perceived risk; volunteers; medical ethics; cost-benefit analysis. evidence of the overall benefit of the procedures tha? they use or advocate.

There was no problem, overtly, when it was possible to believe that most treatments or procedures involve $\phi$ no risk of any serious consequence; and that, for thoses few which were clearly hazardous, the urgency or the benefit greatly outweighed the hazard involved. dangerous 'life saving' operation is ordinarily appropriate even if it only saves most of the lives. A biops involving slight risk should be done to obtain usefui diagnostic information which would influence treat?뭄 ment or clarify prognosis. But basically the problem iథ quantitative. No action or activity is entirely free from risk of some hazardous consequence. In any particutago case the risk may be judged to be trivial, but we means that word trivial? Or it may be judged to besळ large that it outweighs the expected benefit; but isipis then truly large in a quantitative sense, or is it only conspicuous and perhaps unfamiliar type of risk whicio seems to be large? And what are the ethics of using $\mathbb{Q}$ procedure of which the hazards, on average, are judge $F^{\circ}$ to approach the expected benefits, but not to exceed $B$ them. Or what are the ethics of not using a hazardous procedure of this sort? If 'primum non nocere' is taken? to mean that one should never take some risk of causing harm in order to obtain a greater likelihood of substan tial benefit, it is merely a counsel of regrettable timidity.

There are however, plenty of difficulties. Risk i probabilistic, and the existence of a I per cent risk of death from a particular procedure does not identifys which 99 patients will benefit without detriment, and which one will die without any benefit. Even if risks were known for every age of patient and for every stag@ of a disease, the problem would remain: will I do good or harm to this patient?

Moreover, the collection of reliable data even orw average levels of risk is often inefficient, and particu? larly so when the risks are as low as must apply to mose medical procedures. Girdwood (I) in 1974, compared the number of deaths reported to the then Committee on the Safety of Drugs as being possibly due to dif ferent medicaments, with the number of prescriptions issued by general practitioners for these drugs. On this? very approximate basis, I80 commonly used drugso were associated with less than one death per milliong 
prescriptions. For I 9 drugs the number of deaths lay between I and 20 , and for one drug the rate was about I50 deaths per million prescriptions.

This appears reassuring. Yet when thiourea derivatives had been found to inhibit thyroid activity in animals, thiouracil was widely used to control hyperthyroidism in Man, either to avoid the need for subtotal thyroidectomy, or at least to restore the thyroid activity to normal at the time of operation. Within a few years of its introduction, however, three reports ( 2 , $3,4)$ had appeared, which showed a mortality from agranulocytosis of 0.4 per cent of patients treated with thiouracil; a risk 25 times greater than Girdwood's highest value. If safer and equally effective derivatives of thiourea had not rapidly become available, the problem would have been whether to accept the commonly high risks of thyroidectomy in a still toxic patient, or the combined risks of preparation for surgery with thiouracil and the greater safety of operating on a euthyroid patient. Essentially, the problem would have been, not only ethical, but also numerical.

The risks of thiouracil treatment were fortunately identified early in its clinical use. When radiological screening was introduced in Japan, however, for the early detection of gastric carcinoma, which is the commonest cause of death from cancer in Japan, there could be no early prospect of establishing by observation whether more deaths from this malignancy would be prevented by such screening than might be caused by the radiation exposures involved. The mean latency for development and detection of radiation-induced cancers is probably of 20 or more years; and after such a period of time, the overall difference in mortality between screened and unscreened populations might be difficult to establish statistically, even if it had been thought ethically sound to pursue a large unvalidated screening programme, with unscreened controls, for several decades. In this case, however, the risk estimates for cancer induction by radiation had been rather reliably established for a number of organs (5). It was therefore possible to form an estimate of the approximate number of cancers, both of the stomach and of other organs, that might ultimately be induced by the radiation doses to the various tissues exposed during such annual screening of healthy populations. These estimates were combined, by Iinuma and his colleagues in $1979(6)$, with data on the number of stomach cancers that would be detected by such examinations at different ages, and the reduction in mortality achieved by their detection. These estimates were possible because, already by 1978,4 million people were being screened annually in Japan for stomach cancer. On the basis of these data, it appeared that screening at ages greater than about 30 in either sex should increase life expectancy, by cancer detection, but screening at younger ages should reduce it, by cancer induction.

This analysis appears, and was admitted to be, tentative, approximate and complex; but what is a better alternative? Is it ethically sound to screen without seek- ing to estimate whether more harm is being done than good, or to refrain from screening for fear more harm would, on balance, be caused? Or, if screening is being practised, is it ethically sound simply to guess at the age below which screening might be positively harmful?

In this instance, one aspect of the problem at least made for simplicity: the comparison was of like with like, of cancer deaths with cancer deaths. Using evidence of the average latency of radiation induction of cancers, the increase in life expectancy was assessed according to the estimated numbers of early deaths prevented and later deaths induced.

In other cases, the comparison is more difficult. From 1967 to 1976 , an average of 3.3 deaths per year in England and Wales were attributed (7) to the effects of vaccinations (deaths registered in International Classification of Diseases - ICD - categories E 933 and 934). During the same period 3.7 million vaccinations were reported (8) as having been carried out (against eight major types of infective disease), suggesting a low risk of death of about $I$ in a million from vaccinations as used during that period. Even if only the deaths were considered however, and compared with the number of deaths in unvaccinated children from these diseases, parents would view very differently a death due to their decision that their child should be immunised, and a death due to their omission, or unwillingness, to do so. Mathematically, and perhaps in simple terms of public health, it is preferable to accept a risk of causing one death than to allow more than one to occur naturally. Emotionally it may not be so easy.

The problem is difficult even if the risk can be expressed in clear cut terms - a probability of certain defined permanent or temporary disabilities - but the benefits cover a range of improvements in health or in the quality of life. The perceived value of different harms or benefits will not be the same to different patients, or to patients and their doctors. If an operation carried a 5 per cent mortality, but gave a 50 per cent chance of radically removing a cancer which would otherwise cause death after a mean period of two years, it would be easy to calculate the average gain in life expectancy conferred by the operation on a man of stated age; but it would be difficult to know what relative weights he would attach to survival during the next two years, and to survival during a subsequent 20 years; and the quality of life may enter the calculation as strongly as mere survival.

Radiotherapy was at one time widely given to relieve the pain and limitation in severe ankylosing spondylitis. It was however found in I965 (9) that patients so treated had an increased risk of death from leukaemia following the bone marrow irradiation involved in the treatment, and from cancers of other heavily irradiated organs. Consequently the use of radiotherapy in this condition was largely abandoned. Alternatively, ankylosing spondylitis had been effectively treated in various clinics in Germany by intravenous injections of a short half-lived isotope of radium (radium-224). The radiations from this radio- 
nuclide, when it became concentrated in bone, had had a similar beneficial effect on the adjacent spinal joints to that of external radiotherapy. This treatment also however was found (I0) to carry an increased risk of induced fatal malignancies, in this case of bone sarcoma, and has largely been abandoned in consequence.

The risks of later death from induced malignancies were of about I per cent following the treatment by external radiotherapy, and probably about 4 per cent after the radium injections. These fatality rates seem so high that safer alternatives should certainly be used if they are equally effective. It is not self-evident, however, that there might not be patients who would wish to accept a I per cent or greater risk of death from malignant disease many years later, if effective relief from a painful and disabling disease was not obtainable otherwise. Perhaps the ethical issue here is whether these therapies were abandoned because they were recognised as causing cancer, which for any physician would be a compelling reason, or because of the probability with which they caused it.

In a report to the World Health Organisation (WHO) (I I), the difficult problem of the risks taken by volunteers is considered in the context of research involving radiological investigations. The risk of causing either a fatal malignancy in the volunteer, or any substantial inherited defect in his or her progeny, are estimated for investigations involving different levels of radiation exposure - whether by conventional $x$-rays or in nuclear medicine studies. Most such procedures deliver radiation doses of less than 0.5 millisieverts (WHO's Category I; I millisievert in Système International des Unités [SI] units corresponds to 100 millirem in former units) or of between 0.5 and $5 \mathrm{mSv}$ (Category II). These are doses comparable with the 2 $\mathrm{mSv}$ received annually from natural sources of radiation. At these diagnostic dose levels, the risks of inducing a fatal cancer are likely to be in the region of 2 per million, and 2 per 100,000 for studies in Categories I and II respectively; and those of causing inherited defect are on average about half as high.

Risks of these sizes are difficult to grasp. In an individual who had volunteered for five separate studies in the higher of these risk categories, the probability of dying from malignant disease would be increased from the normal value of 22 per cent to 22 .0I per cent. Or, put otherwise, if each research in this higher category involved 30 volunteers, one death from cancer, or one inherited defect, would result from every 1000 research projects.

Such numbers do not solve problems, but they do allow some perspective to the investigator and to his ethical committee, and even perhaps to the volunteer. Viewed simply in terms of benefit and harm, it is easy to feel that the planning and approval of research would be either very bad or very unlucky if 1000 research projects did not result, worldwide and in the future, in the saving of one life. With risks of this low order it becomes relevant also to compare the safety of the investigation with that of simply reaching hospital or clinic to have it done. The child who comes ten times by car to have his height and weight measure will already have earned a fatality risk of more than $\bar{\phi}$. per million from traffic accidents if he lives more than ten miles away (12). And these are levels of risk which must be exceeded every few minutes on the mountai by those who volunteer to join search parties to save lives in verglas (iced-rock) or avalanche conditions. single individual known to be at risk is a more comper ling objective than a statistical probability of a doze lives that might be saved; but how much more? is

Many of the difficulties in assessing the acceptabilit $\bar{\phi}$ of medical risks result from inadequate knowledge of the size of the risk, or of the way the risk varies wit/s identifiable features of the patient's condition and perhaps of the available medical facilities. More uncer tainties come from the even greater deficiency in estipo mates of the possible or expected benefits. Liver biopsy used to have an average fatality of about $I$ in 5099 in the 1950 , which fell to $I$ in 5000 in the I960s witb the introduction of the Menghini needle (13). What is the size of the benefit? Were the risks high enough te exclude liver biopsy in distinguishing between hazar $\$$ ous conditions requiring different forms of treatment Presumably not. Were they low enough to justify biopsy if it could not influence treatment but might guide prognosis: probably so in many patients but no $\overrightarrow{0}$ in all. The benefit of selecting the appropriate treatro ment might be simple to evaluate quantitatively; of assessing prognosis might not. And each estimatêfof benefit would depend additionally on a range of idertt fiable clinical factors, as indeed the risk of the prot cedure itself must depend, for example on liability to bleeding from dilated capsular veins or from reduced prothrombin levels.

The difficulty of adding incommensurable com ponents of risk, or comparing them with incommen surable aspects of benefit, is often thought of as negating the value of risk assessment or risk benefit com parisons. Certainly the arithmetical addition of apples and pears is bad practice - whether the apples are immediate deaths and the pears are late ones, or the apples are anxieties relieved and the pears are the hazards of a biopsy that may relieve them. But it is hard to believe that some quantitative assessment of the benefits and the risks, the numbers of apples and pears, would not be of some help in reaching decisions. or giving advice. And certainly it should be of morf help than merely acknowledging that there is fruit of each side of the equation.

In some situations the question is posed differently, in terms of a cost-benefit relationship. How cosk effective in saving lives are renal transplants or dialyzer $\frac{0}{2}$ or, for that matter, motorway crash barriers? How cost-effective in saving lives is the elimination of smallpox? Such questions seem medically obnoxious requiring as they do a cash evaluation of human life (except for the smallpox one, which must win hand down on any criterion, having been achieved at a cose to WHO - on a rather precarious economic argumen 
(13) - of $£$ Io per life saved). In fact, however, the 'cost' of a life need not enter the equation (if one can make the rather gratuitous assumption of a medically benevolent Treasury which would allocate for more effective clinical purposes the sums saved by suspension of less effective ones). The question is finally one of whether available finance is more effectively spent in saving lives in this way or that way. Nor need the cost of a life or of health enter the choice between medical alternatives generally, except perhaps in some cases as a surrogate kind of weighting factor between, for example, periods of health, of activity lost owing to major or minor disability, and equal periods of being dead.

In some form or other, however, considerations of risk and of benefit to the patient or to the community lie at the heart of all medical practice; and comparisons of risk and benefit have always influenced clinical decisions implicitly. Too often, however, these decisions have needed to be made with little or no factual knowledge of the size of the risks involved, or of the factors which influence their size in different patients or in different conditions. Too often no objective comparison can be made even between the risks of conventional alternatives. And yet some consideration of overall benefit or harm is ethically essential, however inadequate our present estimates of risk may be, and however many other factors than the average value of the risk must influence individual decisions.

\section{Table ra Fatality risk of medical procedures}

Drugs, per prescription I974, commonly less

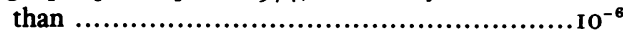

Vaccinations, $1967 / 76$, against 8 diseases $\ldots \ldots \ldots . .1 \times 10^{-6}$

Anaesthesia in major surgery $1973 \ldots \ldots \ldots \ldots \ldots .4 \times 10^{-5}$ falling from $6 \times 10^{-4}$ in 1951

Childbearing, risk per maternity $1976 \ldots \ldots \ldots \ldots \mathrm{I} \times \mathrm{IO}^{-4}$ falling from $5 \times 10^{-4}$ in 1953

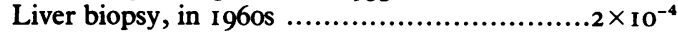
falling from $2 \times 10^{-3}$ in 1950 s

Treatment with thiouracil $1943 / 45 \ldots \ldots \ldots \ldots \ldots \ldots .4 \times 10^{-3}$ $\mathrm{x}$-ray treatment of ankylosing spondylitis $\ldots \ldots \ldots . \mathrm{I} \times \mathrm{IO}^{-2}$

Radium-224 treatment of ankylosing spondylitis $\ldots \ldots \ldots \ldots \ldots \ldots \ldots \ldots \ldots \ldots \ldots . . . \ldots \times 11^{-2}$

Use of thorotrast as arteriographic contrast medium $6 \times 10^{-2}$

Table Ib Annual UK occupational fatality risks

(1974/78 except as stated)

Manufacture of clothing and footwear $\ldots \ldots \ldots . . .4 .0 \times 10^{-6}$ Manufacture of vehicles ....................... $1.5 \times 10^{-5}$ Manufacture of timber, furniture, etc $\ldots \ldots \ldots . . .0 \times 1.0 \times 10^{-5}$ Chemical and allied industries $\ldots \ldots \ldots \ldots \ldots \ldots \ldots . .5 \times 10^{-5}$ Shipbuilding and marine engineering $\ldots \ldots \ldots \ldots . . .1 .0 \times 10^{-4}$ Agriculture (employees) $\ldots \ldots \ldots \ldots \ldots \ldots \ldots \ldots \ldots . .0 \times 10^{-4}$ Construction industries $\ldots \ldots \ldots \ldots \ldots \ldots \ldots \ldots \ldots \ldots . .5 \times 10^{-4}$

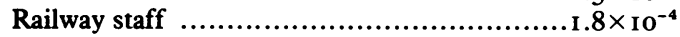
Coal miners ................................... $1 \times 10^{-4}$ Quarrying .................................. $3.0 \times 10^{-4}$ Offshore oil and gas workers $(1967 / 76) \ldots \ldots \ldots .1 .6 \times 10^{-3}$ Deep sea fishing (accidents at sea only, I 959/68) $2.8 \times 10^{-3}$
It would seem important therefore, to review and extend those numerical estimates of risk that we already have. Their very wide range of values, with risks of death from different conventional procedures ranging over several orders of magnitude, suggests that even such tentative and approximate risk estimates can be of guidance in decision-making.

It is also informative to compare these levels of medical risk with those arising in different contexts, where the fatality rates range equally widely, for example in different conventional occupations, forms of travel or types of sport (See Tables). Such comparisons do not address the questions of the relative acceptability or justification of different risks. They may however offer a better perspective on the size of various risks than simply to express these sizes in negative powers of ten; and they certainly emphasise that activities which may appear comparable in the presence or absence of hazard, may in fact differ very greatly in the actual levels of risk observed.

There are certainly likely to be better indices of the harm of a practice than simply the probability that it may cause death. For example, the average length of time lost, and the periods of impaired health or activity, give a rather fuller expression of the harm that the practice may cause (14). In this way, the occupational risks of an industry could be expressed in terms of the sum of several components, presumably with appro-

Table Ic Risk of fatality to passenger, per I00 miles travelled, UK $1972 / 76$

By rail (train accidents) $\ldots \ldots \ldots \ldots \ldots \ldots \ldots \ldots \ldots . . .0 \times 10^{-6}$

In public service vehicles $\ldots \ldots \ldots \ldots \ldots \ldots \ldots \ldots \ldots . .9 \times 10^{-5}$

By UK airlines (scheduled services) $\ldots \ldots \ldots \ldots \ldots 2.2 \times 10^{-5}$

By car or taxi .............................. I $1 \times 10^{-4}$

By pedal cycle $\ldots \ldots \ldots \ldots \ldots \ldots \ldots \ldots \ldots \ldots \ldots \ldots \ldots . .4 \times 10^{-3}$

By motorbicycle, etc ('2 wheeled motor vehicles') driver $\ldots \ldots \ldots \ldots \ldots \ldots \ldots \ldots \ldots \ldots \ldots . . .6 \times 10^{-3}$

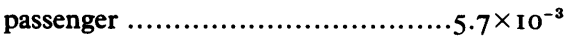

Table Id Risk of death in sporting activities Scuba diving (UK, sub-aqua club members

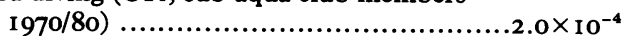

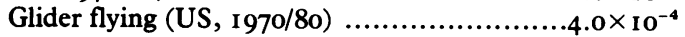
Power boat racing (US, $1970 / 78) \ldots \ldots \ldots \ldots . . .8 .0 \times 10^{-4}$ Hang gliding (UK, Hang Gliding

Association $1977 / 79) \ldots \ldots \ldots \ldots \ldots \ldots \ldots \ldots .5 \times 10^{-3}$ Sport parachuting (US, 1978$) \ldots \ldots \ldots \ldots \ldots \ldots . .2 .0 \times 10^{-3}$

Amateur boxing (UK, I946/62) per participant hour Skiing (US, $1967 / 68$, France $1974 / 76$ ) about $\ldots . . . \ldots . .10^{-6}$ Canoeing (UK, $1960 / 62) \ldots \ldots \ldots \ldots \ldots \ldots \ldots \ldots \ldots . . . \ldots \ldots 0^{-5}$

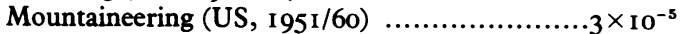

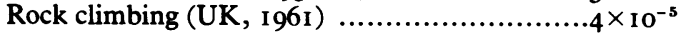


priate weighting factors for each: the absolute loss of life expectancy, as assessed from the annual frequency of deaths from accident and induced disease, with the ages at which such deaths occur and the normal life expectancy at these ages; the average annual loss of normal activity, as judged by the recorded numbers of days off work resulting from occupational injuries and diseases; and the annual frequency of permanent complete or partial disability, with the ages at which such disabilities occur.

A similar criterion could be applied to other hazards. The risk of death from disease attributable to smoking can be assessed at a rate of rather over $10^{-6}$ per cigarette smoked. Such deaths, if they occur, occur at ages which involve an average loss of about 15 years of life expectancy. On this basis, and ignoring the periods of sickness preceding death from the lung cancers and cardio-vascular disease, smoking could be described, perhaps rather absurdly, as involving an average loss of life expectancy at the rate of about one and a half hours per packet of ten.

It is, at the same time, important to recognise that different individuals will 'perceive' the risk of a given situation or procedure very differently, in part from lack of information, or misconceptions, as to the magnitude of components of the actual risk, but much more because of varying opinions about the unpleasantness of different types of risk, and perhaps also from a more realistic assessment of the importance of anxiety than will ordinarily enter any evaluation of the magnitude of risks. This whole field of 'perceived risk' deserves closer and more critical study, and not least in regard to medical risks. In other connections it has been pointed out that different weights will be attached to risks of equal size, according to whether, for example, these risks are regarded as self-chosen, or imposed by authorities, or by their nature unavoidable, or involving immediate or delayed harm. For example, in the field of radiation protection, uranium and other hardrock miners are exposed to a risk of accidental death from rock falls and other traumatic events, and to a rather smaller risk of death from lung cancer induced by inhalation of radon and its radioactive daughter products. The occupational mortality rate is presumably to be assessed as the sum of both risks; but what relative weights should be given, or are given in the miners' opinion, to an immediate traumatic death at the time of the accident, and to a death from cancer, but from a cancer which only develops some 20 years after the causative radiation exposure.

Similarly in medicine, the proper review of risk and of benefit, and the assurance that overall benefit is obtained with minimised risk, can never be a simple matter of knowing the probabilities and doing the arithmetic. Different weights must apply to different benefits and different types of risk. Yet the weightings will not be the same in the mind of the informed surgeon or physician, and in that of the anxious patient or his family; and it is the benefit or risk to the patient that is at issue. It must be ethically important to adopt a course of action which the patient perceives as giving him the greatest benefit; but it must be ethically eve more important to offer suitable advice as to which course of action seems likely to ensure the greatesi. objective benefit. Such advice must take many cong siderations into account; but one consideration should surely be based on knowledge of the probability af different consequences of the action.

Quantitative evaluation of risk has a long way to go and that of benefit perhaps even further. Ethicallyo however, it seems important to develop these forms of objective assessment as one essential component iP decision making in many fields, and not least $\overrightarrow{i n}$ medicine.

\section{References}

(I) Girdwood R H. Death after taking medicaments. Britist medical journal I974; I: 501-504.

(2) Moore F D. Toxic manifestations of thiouracil therapy Fournal of the American Medical Association 1946; 130:315-319.

(3) van Winkle W Jr, Hardy S M, Hazel G R et al. Th $\$$ clinical toxicity of thiouracil. Fournal of the Americas Medical Association 1946; 130: 343-347.

(4) Fowler E F. Treatment of hyperthyroidism wit\$ thiouracil, with particular reference to toxic reactions International abstracts of surgery 1946; 83: 313-322. $\bigcirc$

(5) United Nations Scientific Committee on the Effecto of Atomic Radiation. Sources and effects of ionizing ractios tion, 1977 report to the General Assembly. UN Salest E77 IX I. New York: United Nations, I977.

(6) Iinuma T A, Tateno Y, Umegaki Y, Hashizume TA Benefits vs risk analysis of stomach cancer mass screen ing. In: Okada J et al eds. Radiation research: proceedings of the Sixth International Congress of Radiation Research. Copyright Japanese Association for Radiation Research? Tokyo, 1979: 980-988.

(7) Office of Population Censuses and Surveys. Mortalit. statistics of childhood and marternity. $\mathrm{DH}_{3} \mathrm{No}_{4}$, London HMSO, 1977. Birth statistics. FMI No 3, Londor HMSO, 1979 .

(8) Government Statistical Service. Thomson E J ed. SociąD trends. Vol 9. London: HMSO, 1979.

(9) Court Brown W M, Doll R. Mortality from cancer an\& other causes after radiotherapy for ankylosing spondylitis. British medical joumal 1965; 2: 1327-1332.

(10) Spiess H, May C W. Protraction effect on bone sarcoma induction by $224-\mathrm{Ra}$ in children and adults. In Radionuclide carcinogenesis. Washington: US Atomico Energy Authority Symposium, Series No 29, 1973: 437-

(I ) World Health Organisation. U se of ionizing radiation and radionuclides on human beings for medical research, traintv ing and non-medical purposes. Report of a WHO expent committee. Technical report series No 6i I Genevas WHO 1977.

(12) Department of the Environment. Transport statisticas Great Britain 1966-76. London: HMSO, 1978.

(13) Pochin E E. Quantification of risk in medical procedures. London: Proceedings of the Royal Society, 1981; Series A: 376: 87-ror .

(14) International Commission on Radiological Protection Publication 27. Problems involved in developing an inde 2 of harm. Annals of the ICRP, I978; I(4): I-24. 


\section{References}

(1) An earlier version of this paper was read at the Society for Applied Philosophy's Workshop on Philosophical and Ethical Issues in Medicine at its meeting in Manchester on 12 November 1983: my thanks to participants for their criticism; and to David Rea for his comments.

\section{Commentary}

\section{Hugh Cannell, The London Hospital Medical College}

Brecher argues that ambulance drivers, nurses, doctors and other hospital workers do not have special moral obligations that prevent them from striking in circumstances where workers without those special obligations would be justified in striking. I wish to argue against this position. People voluntarily undertaking work in the emergency services, implicitly or explicitly undertake co-operatively to provide these emergency services. Since striking is not compatible with such a provision, implicitly they undertake not to strike. This does not, as Brecher alleges, mean that they have a special obligation not to give up the job - for given reasonable notice it is generally possible to find replacements so that the emergency service can be maintained.

There is no reason to argue that because some workers do not accept the special moral obligations of providing emergency services, therefore no workers can or should accept the special moral obligations. Indeed it is patently obvious that such 'moral relativism' exists. While there is no moral obligation to take on such supererogatory commitments, once one has taken them on there is a moral obligation to honour them. Brecher states 'either there are or there are not moral grounds why people ought to become ambulance drivers, ought, that is, to take on, among other things, the special obligation in question. If there are such grounds, then I cannot see that they could fail to apply to everyone . . . It is obvious that there are many voluntary moral obligations that people are free to undertake but which do not apply to everyone. What does apply to everyone is that moral undertakings should be honoured.

Volunteer life-boat men are obvious examples. They voluntarily commit themselves to accept the special obligations of the task, including the very special obligation to provide an emergency service at great risk to themselves. Why should the moral obligations undertaken in volunteering for unpaid life-saving work differ so greatly from those voluntarily taken in paid life-saving work? Emergency workers including ambulance men voluntarily accept the special moral obligations of their callings and are aware (often with pride) of the special risks and burdens which are involved. It seems an implicit part of those burdens that the normal strike weapon is eschewed, and it may be sensible to make this explicit in the contract of employment. Such work has its own intrinsic satisfactions, including a certain moral satisfaction. To incorporate an explicit 'no-strike clause' seems justifiable not only on the grounds that it is wrong to inflict suffering on innocent and already sick third parties in order to achieve one's own economic ends but also on the general utilitarian grounds, that welfare is likely to be maximised by such arrangements. If these in practice resulted in inadequate recruitment, no doubt this could be remedied by adjusting wages perhaps also by linking these to the wages of other groups not morally bound by no-strike agreements.

Two final points: To use words such as 'strike', 'weapon' or 'threat' in debates about ethical issues implies a bellicose if not a non-moral stance. Furthermore the acceptance of the term 'strike' as being synonymous with 'not working' rather than seeing it as a withdrawal from an agreed contract, would appear to beg the moral issues involved.

\section{Correction: Risk and medical ethics, Pochin, E. Journal of Medical Ethics 1982, 8: 180-184.}

The author has asked us to correct the heading to Table 1c. Instead of reading Risk of fatality to passenger, per 100 miles travel, UK 1972/76' it should have read 'Percentage risk of fatality to passenger, per 100 miles travel, UK 1972/76'. The author adds that he very much regrets the error.

Editor 